\title{
PURIFICAÇÃO DE COMPLEXO CELULOLÍTICO DE Aspergillus niger USANDO SISTEMA AQUOSO DE DUAS FASES COM PEG-CITRATO
}

\author{
J. FISCHER ${ }^{1}$, V. S. LOPES ${ }^{1}$, E. F. Q. SANTOS ${ }^{1}$, C. Z. GUIDINI ${ }^{1}$, L. RAMADAN ${ }^{1}$, U. C. \\ FILHO $^{1}$, V. L. CARDOSO ${ }^{1}$ \\ ${ }^{1}$ Universidade Federal de Uberlândia, Faculdade de Engenharia Química. \\ E-mail para contato: janaffischer@hotmail.com
}

\begin{abstract}
RESUMO - Celulases são enzimas que constituem um complexo capaz de hidrolisar materiais celulósicos, liberando açúcares possíveis de serem convertidos em etanol durante a fermentação alcoólica. Neste trabalho, investigou-se a purificação e a utilização de complexo de celulase purificado pelo sistema de duas fases com polietilenoglicol (PEG) e citrato de sódio. O complexo enzimático bruto foi gerado por fermentação em estado sólido por Aspergillus niger e meio composto por farelo de arroz (60\%) e bagaço de cana tratado com explosão a vapor (40\%). Posteriormente, foi purificado com PEG de massa molar 2000-6000 g/mol. Os melhores resultados foram obtidos com o uso de PEG 2000 em concentração de $22 \%$ e pH 7,0, observando-se que a purificação não ocorre de forma homogênea para todas enzimas do complexo e revelando que, entre as enzimas $\beta$-glicosidase, endoglucanase e exoglucanase, a endoglucanase apresentou maior fator de purificação $(\mathrm{FP}=2)$.
\end{abstract}

\section{INTRODUÇÃO}

Materiais lignocelulósicos, como o bagaço de cana-de-açúcar, são os mais abundantes complexos orgânicos de carbono na forma de biomassa de planta e consistem principalmente de três componentes: celulose, hemicelulose e lignina. $\mathrm{O}$ aproveitamento de resíduos agroindustriais em processos de bioconversão, como fermentação para produção de enzimas e etanol celulósico, tem recebido grande destaque no cenário mundial, devido ao fato de reduzir a poluição ambiental gerada por estes resíduos e ampliar a produção de etanol e a sustentabilidade do processo (Soccol et al., 2010; Rocha et al., 2013).

O complexo enzimático celulolítico consiste de três classes de enzimas que atuam sinergicamente na hidrólise da celulose: endoglucanases (1,4- $\beta$-D-glucan-glucanohidrolase), 


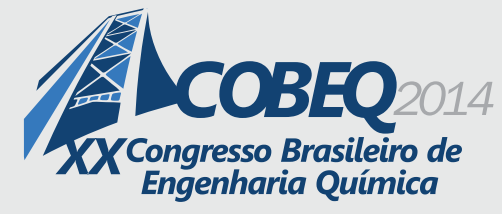

19 a 22 de outubro de 2014

Florianópolis/SC

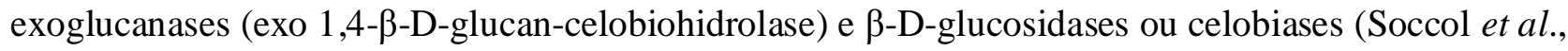
2010). Celulases são produzidas por fermentação submersa (FS) ou fermentação em estado sólido (FES). A grande vantagem da FES é que os resíduos lignocelulósicos podem ser utilizados como substrato (Singhania et al., 2010). Segundo Zhang e Lynd (2004), os fungos são considerados os mais importantes microrganismos utilizados pela indústria na produção de enzimas, sendo que um dos mais utilizados em processos fermentativos é o Aspergillus niger, fungo filamentoso, facilmente adaptável às condições de FES.

A tecnologia enzimática é, atualmente, um dos campos mais promissores dentro das tecnologias para a síntese de compostos de alto valor agregado. O elevado custo de celulase é o principal obstáculo à utilização de biomassa celulósica. Portanto, muitas pesquisas estão sendo desenvolvidas visando à produção de celulases com alta atividade enzimática e estabilidade (Singhania et al., 2010; Zhang et al., 2006). A aplicação das enzimas depende do seu grau de pureza; portanto, a purificação é uma etapa importante para o estudo das propriedades biológicas e moleculares desses biocatalisadores. Atualmente, o processo de separação e purificação de bioprodutos é um segmento muito importante na indústria, pois pode chegar a representar de 80 a 90\% do custo de produção, o desenvolvimento de um processo eficiente e de baixo custo é de extrema relevância (Bassani et al., 2010).

A precipitação de enzimas com sulfato de amônio é uma das técnicas mais utilizada na purificação de enzimas, devido à simplicidade, à precipitação da maioria das proteínas ocorrerem em uma molaridade alta, não promover o aquecimento da solução, apresentar uma densidade que não interfere na sedimentação da maioria das proteínas e promover o efeito de concentração das proteínas (Kanwar et al., 2006). Outro método de purificação é o sistema bifásico aquoso (SBA), que se formam pela adição de soluções aquosas de dois polímeros hidrofílicos, ou polímero e sal, como por exemplo, polietilenoglicol (PEG) e citrato de sódio. Essas substâncias constituem o meio conveniente e adequado para a extração de substâncias de origem biológica, pois a constituição das fases entre $70 \%$ e $90 \%$ de água, proporciona um ambiente ameno para o trabalho, com compostos biologicamente ativos, preservando sua estabilidade molecular e permitindo, assim, seu processamento neste meio (Herculano et al., 2012).

Assim, este trabalho teve por objetivo avaliar a eficiência da purificação de enzimas, produzidas por FES de resíduos agroindustriais e cepa selvagem Aspergillus niger, por dois métodos: sistema aquoso bifásico PEG/citrato de sódio e concentração com sulfato de amônio, visando aplicação na produção de etanol celulósico. 


\section{MATERIAL E MÉTODOS}

\subsection{Microrganismos e Biomassas}

Foi utilizado Aspergillus niger, selecionado entre 66 culturas de fungos coletados do Cerrado do Triângulo Mineiro (Uberlândia/MG) (FISCHER et al, 2013). A levedura utilizada nas fermentações alcoólicas foi a cepa Saccharomyces cerevisiae Y904, produzida pela Mauri Brasil Ind. Com. Ltda, na forma liofilizada. As biomassas utilizadas foram: farelo do beneficiamento de arroz, obtido de uma beneficiadora da região, e bagaço de cana-de-açúcar, pré-tratado com explosão a vapor na condição de baixa severidade, gentilmente cedido pelo CTC (Centro de Tecnologia Canavieira) de Piracicaba/SP. Todos os microrganismos e biomassas foram estocados sob refrigeração $\left(5 \pm 1^{\circ} \mathrm{C}\right)$.

\subsection{Fermentações e purificação de enzimas}

Fermentação em estado sólido (FES): As FES destinadas à produção de complexo enzimático foram realizadas em reator estático, contendo $10^{7}$ a $10^{8}$ células/g de Aspergillus niger (ressuspensas em $40 \mathrm{~mL}$ de água deionizada) e $40 \mathrm{~g}$ de substrato sólido, $24 \mathrm{~g}$ de farelo do beneficiamento de arroz e $16 \mathrm{~g}$ de bagaço de cana-de-açúcar tratado. O tempo de fermentação foi de $72 \mathrm{~h}$ e a temperatura, $30 \pm$ $1{ }^{\circ} \mathrm{C}$. Os complexos enzimáticos foram extraídos com $100 \mathrm{~mL}$ de água deionizada e Tween 80 (1\%) condições conforme Fischer et al. (2013).

Purificação por SAB: A preparação dos sistemas aquosos bifásico para a extração de celulases foi realizado de acordo com metodologia de Herculano et al. (2012), inicialmente os extratos enzimáticos bruto (EEB) foram clarificados, por filtração a vácuo em papel whatman $\mathrm{n}^{\circ} 1$, e centrifugado durante $15 \mathrm{~min} / 4500 \mathrm{rpm}$. Então, os sistemas foram preparados com polietileno glicol de diferentes pesos moleculares $(2000$ e $6000 \mathrm{~g} / \mathrm{mol})$ e sal de citrato de sódio $\left(\mathrm{Na}_{3} \mathrm{C}_{6} \mathrm{H}_{6} \mathrm{O}_{7} 2 \mathrm{H}_{2} \mathrm{O}\right)$ em diferentes percentagens, o $\mathrm{pH}$ dos sistemas foi ajustado com quantidade apropriada de ácido cítrico para manter um valor de $\mathrm{pH}$ de 7,0 ou 8.0 (Tabela 1). As condições desejadas de PEG e sal foram colocados tubos de centrifugação graduados $(15 \mathrm{~mL})$, e $20 \%$ do total do sistema com EEB clarificado foram adicionado aos tubos. Água deionizada foi então adicionada para um peso final de 10,0 g. Após agitação em Vortex durante 1,0 min, as duas fases foram separadas por sedimentação durante $40 \mathrm{~min}$. Os volumes de fases foram medidos, e as fases superior e inferior foram retirados separadamente e analisados. O fator de purificação (PF) foi calculado como a razão entre a atividade específica da fase superior pela atividade específica do extrato enzimático antes da partição.

Precipitação com sulfato amônio: A separação enzimática foi realizada por salting-out utilizando sulfato de amônio nas concentrações de 0,$20 ; 0,30 ; 0,40 ; 0,50 ; 0,60$ e $0,70 \mathrm{~g} / \mathrm{g}$ da mistura sal e extrato enzimático bruto (Tabela 1). Com ajuste de $\mathrm{pH}$ para 6,5 e manutenção da mistura salina a $4 \pm 1{ }^{\circ} \mathrm{C}$ por um período de $12 \mathrm{~h}$ (overnight) seguido de centrifugação a $18900 \mathrm{~g}$ e solubilização do precipitado em água em um volume correspondente a 1/3 do volume inicial. 
Tabela 1 - Condições de purificação por sistema aquoso bifásico e precipitação salina.

\begin{tabular}{|c|c|}
\hline Experimento & Condições de concentração do complexo enzimático \\
\hline A & $20 \%$ PEG $6000 \mathrm{~g} / \mathrm{mol}+10 \%$ citrato de sódio, $\mathrm{pH} 8,0$ \\
\hline $\mathrm{B}$ & $24 \%$ PEG $2000 \mathrm{~g} / \mathrm{mol}+15 \%$ citrato de sódio, $\mathrm{pH} 8,0$ \\
\hline $\mathrm{C}$ & $22 \%$ PEG $2000 \mathrm{~g} / \mathrm{mol}+17,5 \%$ citrato de sódio, $\mathrm{pH} 7,0$ \\
\hline $\mathrm{D}$ & $18 \% \mathrm{PEG} 2000 \mathrm{~g} / \mathrm{mol}+17,5 \%$ citrato de sódio, $\mathrm{pH} 7,0$ \\
\hline $\mathrm{E}$ & $22 \% \mathrm{PEG} 2000 \mathrm{~g} / \mathrm{mol}+17,5 \%$ citrato de sódio, $\mathrm{pH} 7,0$ \\
\hline $\mathrm{F}$ & $26 \% \mathrm{PEG} 2000 \mathrm{~g} / \mathrm{mol}+17,5 \%$ citrato de sódio, $\mathrm{pH} 7,0$ \\
\hline $\mathrm{G}$ & Sulfato de amônio $20 \%$ \\
\hline $\mathrm{H}$ & Sulfato de amônio $30 \%$ \\
\hline $\mathrm{I}$ & Sulfato de amônio $40 \%$ \\
\hline $\mathrm{J}$ & Sulfato de amônio $50 \%$ \\
\hline $\mathrm{K}$ & Sulfato de amônio $60 \%$ \\
\hline $\mathrm{L}$ & Sulfato de amônio $70 \%$ \\
\hline
\end{tabular}

Fermentação alcoólica: a produção de etanol foi realizada com complexo enzimático purificado, com sacarificação e fermentação simultâneas de bagaço de cana-de-açúcar tratado com explosão a vapor e Saccharomyces cerevisiae Y904, em reator batelada de $250 \mathrm{~mL}$ com volume reacional de 100 $\mathrm{mL}$ ( $25 \mathrm{~g}$ de substrato para $100 \mathrm{~mL}$ de extrato enzimático), sobre mesa agitada a $150 \mathrm{rpm}$, por $48 \mathrm{~h}$. As condições adotadas para a fermentação alcoólica foram as mesmas da fermentação com caldo de cana-de-açúcar, temperatura de $35 \pm 1{ }^{\circ} \mathrm{C}, \mathrm{pH}$ de 4,5 e inóculo $30 \mathrm{~g} / \mathrm{L}$.

Métodos analíticos: A determinação de proteínas do complexo enzimático foi realizada de acordo com o método de Lowry (1951) e a atividade enzimática em FPase de acordo com Ghose (1987). A concentração de etanol foi determinada por cromatografia líquida (Shimadzu model LC20A Prominence, coluna Ca Supelcogel), a solução de arraste utilizada foi água deionizada, o fluxo de bomba $0,5 \mathrm{~mL} / \mathrm{min}$, temperatura do forno de $80^{\circ} \mathrm{C}$ e volume de injeção de $20 \mu \mathrm{L}$.

\section{RESULTADOS E DISCUSSÃO}

A Figura 1 representa os resultados de purificação por sistema aquoso bifásico por polietileno glicol e citrato de sódio em diferentes condições de massa molecular. Pode-se observar que a melhor condição de purificação ocorre na fase citrato para menor massa molecular de PEG. Estes resultados são coerentes com os obtidos por Herculano et al., 2012 que utilizaram PEG 3350 e 8000 com 17,5\% de citrato de sódio e pH 7,0. Assim esta condições adicionais de menor massa molecular de PEG foi utilizada em ensaios posteriores, apresentados na Figura 2 que também forneceram melhor purificação na fase citrato. 


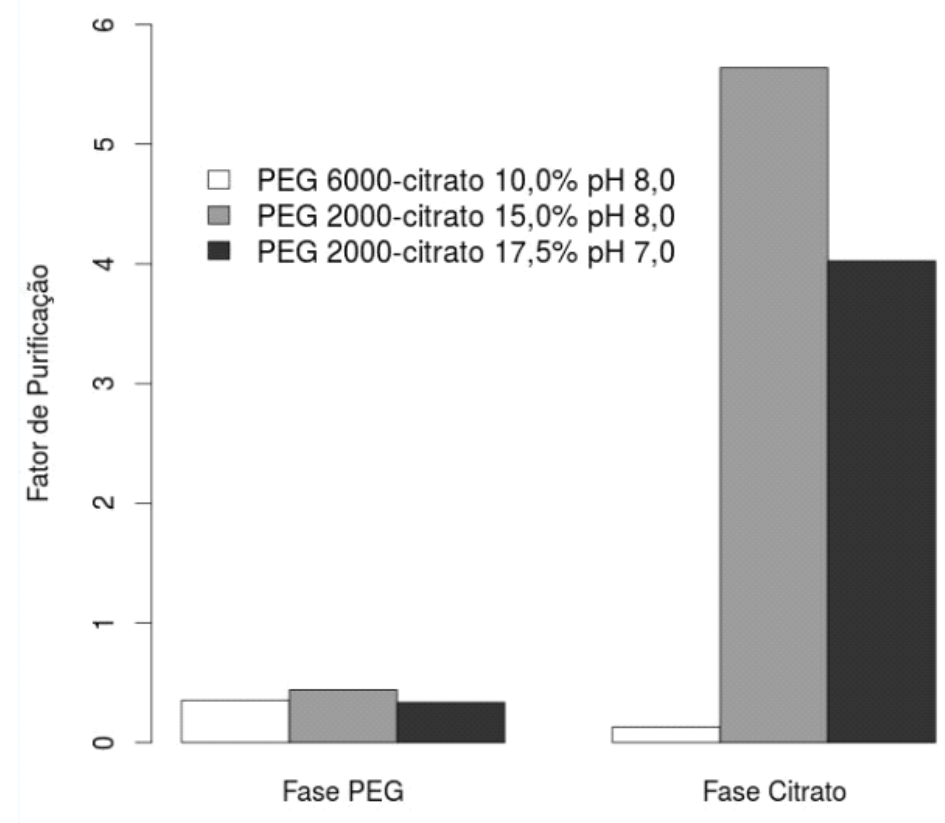

Figura 1 - Fator de purificação para o sistema PEG/Citrato de sódio.

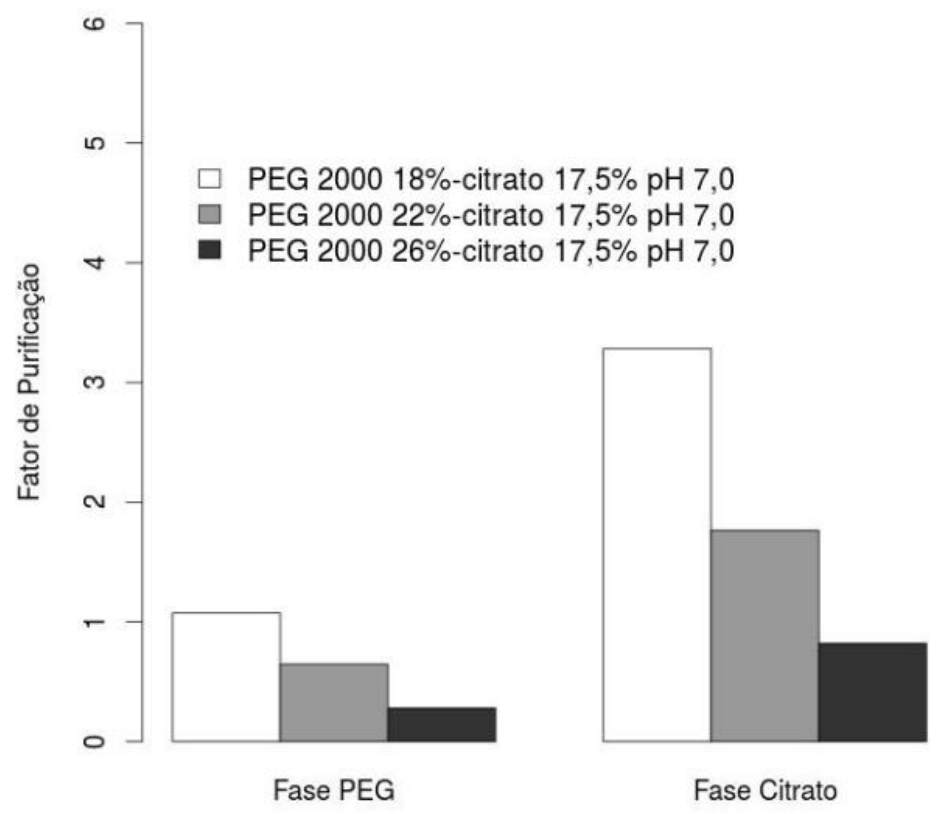

Figura 2 - Fator de purificação para o sistema PEG 2000 g/mol e citrato de sódio. 
Na Figura 3 são apresentados resultados da avaliação da purificação pelo uso de sulfato de amônio, é possível observar que a purificação com sulfato de amônio nas condições testadas não teve efeito como o observado com o sistema de duas fases PEG e citrato (Figuras 1 e 2). Também é possível observar que os melhores resultados foram obtidos para concentração de 40 e $50 \%$ de sulfato de amônio.

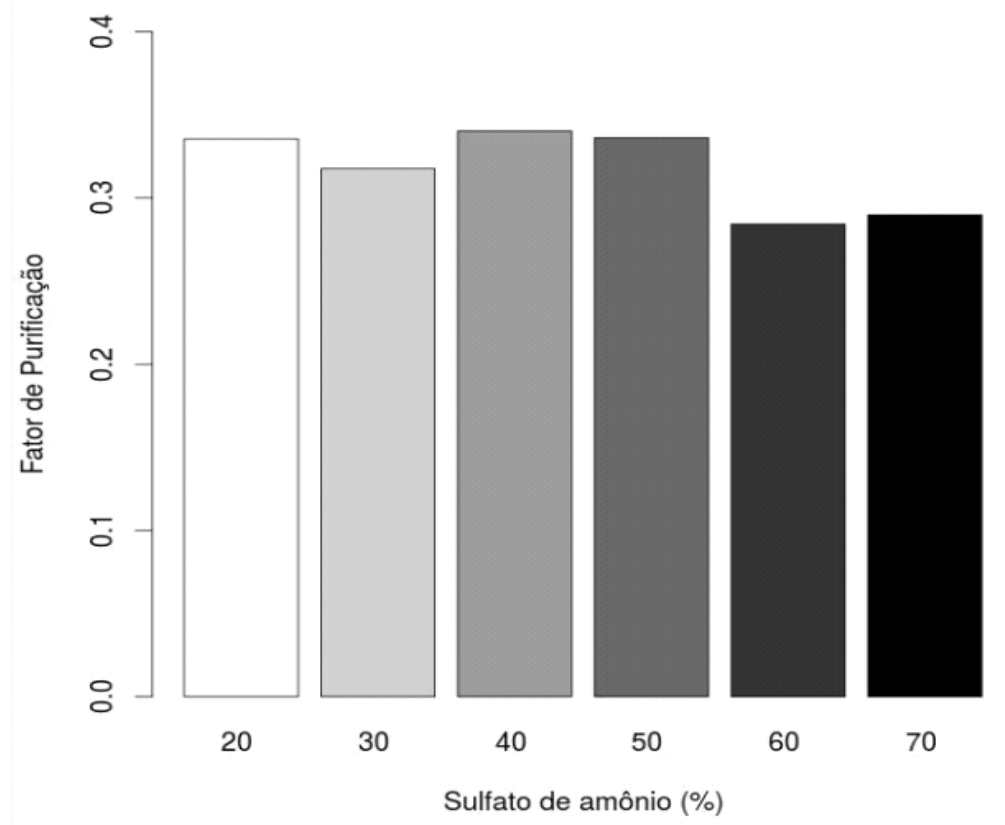

Figura 3 - Fator de purificação para sulfato de amônio.

$\mathrm{Na}$ Tabela 2 são apresentadas as concentrações de etanol obtidas pelo uso de complexo enzimático purificado e uso de sulfato de amônio nas melhores condições apresentadas nas Figuras 1 e 3 e em condições de PEG $2000 \mathrm{~g} / \mathrm{mol}$. Pode-se observar que entre as condições testadas a purificação em sistema bifásico se mostrou superior a purificação em sulfato de amônio. Os resultados também indicam que as enzimas no complexo enzimático bruto atuam de forma econômica e eficiente, pois a diferença na concentração de etanol final entre a catálise de complexo concentrado e bruto foi, nas melhores condições, inferior a 7,5\% (comparação entre os ensaios controle e ensaio D). 
Tabela 2 - Produção de etanol dos complexos enzimáticos purificados.

\begin{tabular}{|c|c|}
\hline Experimento & Etanol (g/L) \\
\hline Estrato enzimático bruto (controle) & 8,7 \\
\hline D (18\% PEG 2000) & Fase PEG: 5,6/ Fase Citrato:9,4 \\
\hline E (22 \% PEG 2000) & Fase PEG: 3,9/ Fase Citrato:5,1 \\
\hline F(26\% PEG 2000) & Fase PEG: 5,8/ Fase Citrato:4,0 \\
\hline I (40 g sulfato) & 8,9 \\
\hline J (50 g sulfato) & 8,2 \\
\hline K (60 g sulfato) & 6,9 \\
\hline
\end{tabular}

\section{CONCLUSÃO}

A purificação pelo sistema bifásico PEG/citrato mostrou que a fase citrato foi capaz de fornecer maiores atividades e foi mais efetivo na produção de etanol. Embora os sistemas de purificação tenham mostrado capacidade superior ao uso de complexo enzimático os resultados sugerem que o complexo enzimático bruto é bastante efetivo, pois este gerou concentrações de etanol próximas as observadas nas melhores condições com concentração em sistema bifásico e concentração com sulfato de amônio.

\section{AGRADECIMENTOS}

Os autores agradecem ao CNPq (Projeto 550940/2010-3, Edital 046/2009), FAPEMIG (Processo PCE-00089-14) e UFU pelo apoio financeiro e ao Centro de Cultura Canavieira (CTC) pela parceria em estudos conjuntos relacionados à produção de etanol.

\section{REFERÊNCIAS}

BASSANI, G.; FUCIÑOS, P.; PICÓ, G.; FARRUGGIA, B. Candida rugosa lipase Lip1 polyethyleneglycol interaction and the relation with its partition in aqueous two-phase systems. Colloids and Surfaces B: Biointerfaces, v. 75, p. 532-537, 2010.

FISCHER, J.; LOPES, V.; GALVÃO, C.; TEODORO, J.; FILHO, U.; CARDOSO, V. Utilization of Cheese Whey and Cellulosic Biomass for Production of Ethanol by Selected Fungi Strain from Brazilian Savannas. Chem. Eng. Trans., v. 32, p. 1075-1080, 2013. 
GHOSE, T. K. Measurement of cellulase activities. Pure \& Applied Chemistry, Oxford, v. 59, n. 2, p. 257-268, 1987.

HERCUlANO, P. N., PORTO,T. S., MACIELA., M. H.C., MOREIRA, K. A., MOTTA, C. M. S., PORTO, A. L.F., Partitioning and purification of the cellulolytic complex produced by Aspergillus japonicus URM5620 using PEG-citrate in an aqueous two-phase system. Fluid Phase Equilibria, v. 335, 8-13, 2012

LOWRY, O.H., ROSEBROUGH, N.J., FARR, A.L., RANDALL, R.J, Protein measurement with the folin phenol reagent. J. Biol. Chem., v. 193 (1951) 265-275.

MMA - MINISTÉRIO DO MEIO AMBIENTE. O bioma cerrado. Disponível em: http://www.mma.gov.br/biomas/cerrado. Acesso em 08 abril 2014.

ROCHA, N.R.A.F.; BARROS, M.A.; FISCHER, J.; FILHO, U.C.; CARDOSO, V. L. Ethanol production from agroindustrial biomass using a crude enzyme complex produced by Aspergillus niger. Renewable Energy, v. 57, p. 432-435, 2013.

SINGHANIA, R. R.; SUKUMARAN, R.K.; PATEL, A.K. Advancement and comparative profiles in the production technologies using solid-state and submerged fermentation for microbial cellulases. Enzyme Microb. Technol., v. 46, p. 541-549. doi:10.1016/j.enzmictec.2010.03.010, 2010.

SOCCOL, C.R.; VANDENBERGHE, L.P.S.; MEDEIROS, A.B.P.; KARP, S.G.; BUCKERIDGE, M.S.; RAMOS, L.P.; PITARELO, A.P.; FERREIRA-LEITÃO, V.; GOTTSCHALK, L.M.F.; FERRARA, M.A.; BON, E.P.S.; MORAES, L.M.P.; ARAÚJO, J.A.; TORRES, F.A.G. Bioethanol from lignocelluloses: status and perspectives in Brazil. Bioresour. Technol, v. 101, p. 4820-4825, 2010.

ZHANG, Y. H. P.; HIMMEL, M. E.; MIELENZ, J. R. Outlook for cellulase improvement: screening and selection strategies. Biotechnology Advances, 24:452-81, 2006.

ZHANG, Y.I.P.; LYND, L.R. Toward an aggregated understanding of enzymatic hydrolysis of cellulose: non-complexed cellulase systems. Biotechnol. Bioeng, v. 88, p. 797-824, 2004. 